\title{
Oral and Salivary Gland Angiosarcoma: A Clinicopathologic Study of 29 Cases
}

\author{
Julie C. Fanburg-Smith, M.D., Mary A. Furlong, M.D., Esther L. B. Childers, D.D.S. \\ Departments of Soft Tissue (JCFS and MAF) and Oral and Maxillofacial Pathology (ELBC), Armed Forces \\ Institute of Pathology, Washington, D.C.
}

Angiosarcomas of the oral and salivary gland area are extremely rare, mostly presented as case reports. We wanted to study the clinicopathologic features of a series of oral and salivary gland angiosarcomas. Cases coded as "angiosarcoma" were retrieved from the Oral and Maxillofacial Pathology Department of the Armed Forces Institute of Pathology. Patient folders and pathology were reviewed and recorded; immunohistochemistry and follow-up were obtained. Inclusion required oral or salivary gland location, vasoformative growth, cytologic atypia, mitoses, and vascular markers. Skin, bone, and subcutaneous angiosarcomas were excluded. Primary and secondary (metastatic) oral angiosarcomas were included. The 22 primary angiosarcomas involved tongue $(n=9)$, parotid $(n=4)$, lip $(n=4)$, submandibular gland $(n=3)$, and 1 each of soft and hard palate. The 7 secondary angiosarcomas involved the gingiva $(n=4)$ and parotid gland $(n=3)$. Overall, patient ages ranged from 6-90 years (mean, 55 years). There were 15 males and 14 females. Symptoms included a mass with recent enlargement and bleeding. Tumor sizes ranged from $0.8-7.0 \mathrm{~cm}$ (mean, $2.6 \mathrm{~cm}$ ). Histologically, all tumors were vasoformative; $86 \%$ had solid and $17 \%$ had distinctive papillary areas. Eight $(\mathbf{2 8 \%})$ were classified as the epithelioid subtype. Immunohistochemical stains showed that the tumor cells were positive for Factor VIIIrag in 19/21, CD31 in $16 / 19$, CD34 in $7 / 12$, and Ulex in $1 / 1$. Primary tumors were classified as low grade $(n=7$, in all

\footnotetext{
Copyright (C) 2003 by The United States and Canadian Academy of Pathology, Inc.

VOL. 16, NO. 3, P. 263, 2003 Printed in the U.S.A.

Date of acceptance: December 3, 2002.

This work was presented in part at the US/CAP meeting in Chicago, Illinois in February 2002 and published in part as an abstract in Modern Pathology 2002;15(1):13A, Abstract 42.

The opinions and assertions contained herein are the expressed views of the authors and are not to be construed as official or reflecting the views of the Departments of the Army or Defense.

Address reprint requests to: Julie C. Fanburg-Smith, M.D., Department of Soft Tissue Pathology Room 3075, Armed Forces Institute of Pathology, Building 54, 14th Street and Alaska Avenue, N.W., Washington D.C. 203066000; fax: 202-782-9182; e-mail: fanburg@afip.osd.mil.

DOI: 10.1097/01.MP.0000056986.08999.FD
}

locations except salivary gland), intermediate $(n=$ 7 ), and high grade $(n=8)$; all secondary tumors were high grade. Follow-up was available on 14/22 primary and 7/7 secondary angiosarcomas. Of primary tumors, two tongue angiosarcoma patients died at 1 and 9 years, but 4 were alive without disease over a mean of 7.3 years (range, 1-13 years). Four primary salivary gland angiosarcoma patients were alive without disease over a mean of 5.8 years (range, 1-14 years), and 1 had only a late (15 years) metastasis and death (at 20 years). Three primary lip angiosarcoma patients were without disease over a mean of 14.3 years (range, 13-16 years). Of secondary tumors, three salivary gland angiosarcoma patients died within 1 year, and all four secondary gingival angiosarcoma patients died of disease within 3 years. Assessing follow-up of primary oral and salivary gland angiosarcoma patients by grade, 5 patients with high-grade tumors had no evidence of disease over a mean of 7.6 years (range, 1-16 years), 3 patients with intermediate-grade tumors had no evidence of disease over a mean of 12.7 years (range, 11-14 years), 2 patients with intermediate-grade tumors died of disease at 9 and 20 years, 3 patients with low-grade tumors had no evidence of disease over a mean of 6.3 years (range, 1-14 years), and 1 patient with low-grade tumor died of disease at 1 year. Primary oral and salivary gland angiosarcomas, albeit rare, mostly involve the tongue, parotid gland, and lip of adults, often with relatively good outcome. Although the most common angiosarcoma morphology in this area is spindled vasoformative and solid, almost one third of oral and salivary gland angiosarcomas are the rare epithelioid angiosarcoma variant. Most gingival and few parotid angiosarcomas appear to be metastases from other locations, with many patients succumbing to death within 3 years. Despite predominantly high- or intermediate-grade morphology, patients with primary angiosarcoma of the tongue, salivary gland, and lip have a better prognosis than do patients with primary cutaneous or deep soft tissue angiosarcoma, including those patients with secondary oral and salivary gland involvement. 
KEY WORDS: Angiosarcoma, Follow-up, Oral, Pathology, Salivary gland, Soft tissue, Vascular. Mod Pathol 2003;16(3):263-271

Angiosarcoma generally occurs in the skin and subcutis or skeletal muscle and has been described in the spleen, bone, liver, and breast (1). Oral and salivary gland area angiosarcomas are extremely rare, comprising only $2 \%$ of a series of all angiosarcomas (2) and 0.6 to $30 \%$ of series or reviews of published head and neck angiosarcomas (excluding scalp) (3-5). Oral and salivary gland angiosarcomas are mostly presented as single case reports $(1,2$, 5-25). Larger head and neck sarcoma studies failed to reveal which angiosarcomas have oral locations (26). In our experience, oral and salivary gland angiosarcoma represent only $1 \%(29 / 2139)$ of all angiosarcoma consultation cases in our files. We wanted to study the clinicopathologic features of a series of angiosarcomas, located specifically in the oral region, including salivary glands.

\section{MATERIALS AND METHODS}

Cases coded as "angiosarcoma" were retrieved from the Oral and Maxillofacial Pathology Registry of the Armed Forces Institute of Pathology. Patient folders and pathology were reviewed and recorded; immunohistochemistry and follow-up were obtained. Inclusion in the study required oral or salivary gland location, vasoformative growth, cytologic atypia, mitoses, and vascular markers. Skin, bone, and subcutaneous angiosarcomas were excluded. Tumors were graded according to previously established criteria (27).

Tissue from all tumors was fixed in formaldehyde and paraffin embedded. Sections (5- $\mu \mathrm{m}$ thick) were stained with routine staining methods. For all cases examined by immunohistochemistry, either available formaldehyde-fixed, paraffin-embedded material or available unstained reserve slides were used. As a detection system, the avidin-biotin complex labeled with peroxidase was employed. Some cases lacked enough material to obtain all or any immunohistochemical stains. Automated DAKO or Ventana autostainers were used. The following primary antibodies/stains were studied: FVIIIrag (polyclonal; pepsin digestion, 1:100 dilution; DAKO Corp, Carpinteria, CA.), CD31 (JC/71, pepsin, 1:40; DAKO), CD34 (Qbend 10; pepsin, 1:40; DAKO), Ulex europaeus lectin (UEA-1, 1:10; EY Laboratories, Inc, San Mateo, CA), cytokeratins (AE1/AE3, keratin cocktail, pankeratins; protease digestion, 1:2, Signet, Dedham, MA), S-100 protein (polyclonal; 1:800; DAKO), melanosome (HMB-45; 1:50, DAKO), desmin (D-33; microwave, 1:40; DAKO), $\alpha$-smooth muscle actin (1E7; 1:8000; Sigma, St Louis, MO), muscle-specific actin (HHF-35; 1:1600; Enzo, Farmingdale, NY), and leukocyte common antigen (CD45RB, predilute, antigen retrieval EDTA, Ventana kit; Tucson, AZ).

\section{RESULTS}

Twenty-nine angiosarcomas included 22 primary (Table 1) and 7 secondary tumors (Table 2). The primary angiosarcomas were from tongue $(n=9$, Figs. $1-3)$, parotid $(n=4)$, lip $(n=4)$, submandibular gland ( $n=3$, Fig. 4 ), and 1 each of soft and hard palate. The secondary angiosarcomas (metastatic to oral and salivary gland location) were in the gingiva ( $n=4$, Fig. 5 ) and parotid ( $n=3$, Fig. 6 ). Patient ages ranged from 6-90 years (mean, 55 years). There were 15 males and 14 females. Symptoms included a mass with recent enlargement and bleeding. Tumor sizes ranged from $0.8-7.0 \mathrm{~cm}$ (mean, $2.6 \mathrm{~cm}$ ). Histologically, all tumors were vasoformative, $86 \%$ (25 cases) had solid and $17 \%$ (5 cases) had distinctive papillary areas. Twenty-eight percent (8 cases) were classified as the epithelioid subtype with large vesicular nuclei, prominent nucleoli, eosinophilic cytoplasm, and cytoplasmic vacuoles containing erythrocytes (i.e., epithelioid endothelial cells). All cases had endothelial cell mitoses; prominent necrosis was present in 11 cases and superficial ulceration, in 7 cases. Most cases had none or only mild lymphocytic inflammation; three cases had a moderate lymphocytic response, and two cases had a severe lymphocytic response. Immunohistochemical stains on paraffin-embedded tissue showed that the tumor cells were positive for Factor VIIIrag in 19/21, CD31 in 16/19, CD34 in 7/12, and Ulex in1/1. Factor VIIIrag and CD31 tended to be more diffuse and CD34 was focal and more difficult to demonstrate when positive (Fig. 7). All cases studied, when material was available, were negative for pankeratin, S100 protein, HMB45, desmin, actins, and leukocyte common antigen. Primary tumors were classified as low grade ( $n=7$, in all locations except salivary gland), intermediate $(n=7)$, and high grade $(n=8)$. All seven secondary angiosarcomas were high grade. All cases were surgically excised; margin status could not be assessed from the submitted consultation material. Of high-grade tumors, two parotid tumors were treated with chemotherapy, and one gingival and one parotid tumor, with radiation therapy.

\section{Follow-Up, Primary Angiosarcoma}

Follow-up was available on 14/22 primary angiosarcoma patients. Follow-up on six (67\%) patients with primary tongue angiosarcomas, over a mean of 6.5 years (range, 1-13 years), revealed that only two patients died at 1 and 9 years. Four primary tongue angiosarcoma patients were alive without 
TABLE 1. Clinicopathologic Data on 22 Primary Oral and Salivary Gland Angiosarcomas

\begin{tabular}{|c|c|c|c|c|c|c|c|c|c|}
\hline Case & Age & Sex & Location & Grade & Morphology* & $\begin{array}{c}\text { Recurrence } \\
\text { or Metastasis }\end{array}$ & Duration & Status & $\begin{array}{c}\text { Time } \\
\text { Interval }\end{array}$ \\
\hline 1 & 30 & $\mathrm{~F}$ & Tongue & High & Epithelioid and solid & No follow-up & N/A & $\mathrm{N} / \mathrm{A}$ & N/A \\
\hline 2 & 62 & M & Tongue & High & Epithelioid and focal & No follow-up & $\mathrm{N} / \mathrm{A}$ & $\mathrm{N} / \mathrm{A}$ & $\mathrm{N} / \mathrm{A}$ \\
\hline 3 & 24 & $\mathrm{~F}$ & Tongue & Inter-mediate & Solid & None & N/A & NED & 11 years \\
\hline 4 & 30 & $\mathrm{~F}$ & Tongue & Inter-mediate & Solid & None & N/A & NED & 13 years \\
\hline 5 & 68 & M & Tongue & Inter-mediate & Solid & Not known & N/A & DOD & 9 years \\
\hline 6 & 6 & $\mathrm{~F}$ & Tongue & Low & Solid & No follow-up & $\mathrm{N} / \mathrm{A}$ & N/A & N/A \\
\hline 7 & 30 & M & Tongue & Low & Solid (focal) & None & N/A & NED & 4 years \\
\hline 8 & 65 & M & Tongue & Low & Solid & Not known & N/A & DOD & 1 year \\
\hline 9 & 83 & $\mathrm{~F}$ & Tongue & Low & Vasoformative & None & $\mathrm{N} / \mathrm{A}$ & NED & 1 year \\
\hline 10 & 66 & $\mathrm{~F}$ & Parotid & High & Solid & None & $\mathrm{N} / \mathrm{A}$ & NED & 1 year \\
\hline 11 & 66 & M & Parotid & High & Solid & None & N/A & NED & 3 years \\
\hline 12 & 90 & $\mathrm{~F}$ & Parotid & High & Solid & No follow-up & N/A & N/A & N/A \\
\hline 13 & 58 & $\mathrm{~F}$ & Parotid & Inter-mediate & Solid & $\begin{array}{c}\text { Metastasis to } \\
\text { lung }\end{array}$ & 15 years & DOD & 20 years \\
\hline 14 & 59 & M & Submandibular & High & Solid & None & N/A & NED & 5 years \\
\hline 15 & 38 & $\mathrm{~F}$ & Submandibular & Inter-mediate & Solid & None & N/A & NED & 14 years \\
\hline 16 & 47 & M & Submandibular & Inter-mediate & Solid & No follow-up & N/A & N/A & N/A \\
\hline 17 & 67 & $\mathrm{~F}$ & Lip & High & Epithelioid and solid & None & N/A & NED & 13 years \\
\hline 18 & 52 & $\mathrm{~F}$ & Lip & High & Epithelioid and solid & None & $\mathrm{N} / \mathrm{A}$ & NED & 16 years \\
\hline 19 & 68 & M & Lip & Inter-mediate & Solid & No follow-up & $\mathrm{N} / \mathrm{A}$ & $\mathrm{N} / \mathrm{A}$ & N/A \\
\hline 20 & 18 & M & Lip & Low & Papillary & None & N/A & NED & 14 years \\
\hline 21 & 16 & M & Soft palate & Low & $\begin{array}{l}\text { Very focal epithelioid } \\
\text { papillary, and solid }\end{array}$ & No follow-up & $\mathrm{N} / \mathrm{A}$ & N/A & N/A \\
\hline 22 & 82 & M & Hard palate & Low & Solid & No follow-up & N/A & $\mathrm{N} / \mathrm{A}$ & N/A \\
\hline
\end{tabular}

* All tumors have vasoformative areas.

$\mathrm{M}=$ male; $\mathrm{F}=$ female; $\mathrm{N} / \mathrm{A}=$ not applicable; $\mathrm{DOD}=$ died of disease; $\mathrm{NED}=$ no evidence for disease.

TABLE 2. Clinicopathologic Data on Seven Secondary (Metastatic) Oral and Salivary Gland Angiosarcomas

\begin{tabular}{|c|c|c|c|c|c|c|c|c|c|c|}
\hline Case & Age & Sex & Location & Grade & Morphology* & $\begin{array}{l}\text { Metastatic from } \\
\text { which Primary } \\
\text { Location }\end{array}$ & $\begin{array}{l}\text { Recurrence or } \\
\text { Metastasis }\end{array}$ & Duration & Status & $\begin{array}{c}\text { Time } \\
\text { Interval }\end{array}$ \\
\hline 1 & 71 & M & Parotid & High & Solid & Lung? & $\begin{array}{l}\text { Mets to lung and } \\
\text { parotid }\end{array}$ & At presentation & DOD & 1 year \\
\hline 2 & 72 & $\mathrm{~F}$ & Parotid & High & $\begin{array}{l}\text { Epithelioid } \\
\text { (focal) and } \\
\text { solid }\end{array}$ & $\begin{array}{l}\text { Primary skin of } \\
\text { forehead }\end{array}$ & $\begin{array}{l}\text { Met to parotid } \\
\text { and cervical } \\
\text { lymph nodes }\end{array}$ & 2 months & DOD & 1 year \\
\hline 3 & 65 & $\mathrm{~F}$ & Parotid & High & Solid & $\begin{array}{l}\text { Primary temple } \\
\text { skin }\end{array}$ & Met to parotid & Within 1 year & DOD & 1 year \\
\hline 4 & 65 & $\mathrm{~F}$ & $\begin{array}{l}\text { Gingiva, } \\
\text { interdental, } \\
\text { teeth \#27-30 }\end{array}$ & High & Papillary & $\begin{array}{l}\text { Primary skin of } \\
\text { arm, s/p XRT } \\
\text { for breast } \\
\text { cancer }\end{array}$ & Mets to gingiva & 1 year & DOD & 2 years \\
\hline 5 & 65 & M & $\begin{array}{l}\text { Right upper } \\
\text { gingiva }\end{array}$ & High & $\begin{array}{l}\text { Epithelioid, } \\
\text { solid, and } \\
\text { focally } \\
\text { papillary }\end{array}$ & $\begin{array}{l}\text { Primary skin of } \\
\text { forehead }\end{array}$ & $\begin{array}{l}\text { Mets to oral } \\
\text { mucosa }\end{array}$ & Within 2 years & DOD & 2 years \\
\hline 6 & 69 & M & Maxillary gingiva & High & $\begin{array}{l}\text { Epithelioid } \\
\text { and solid }\end{array}$ & Skin primary & $\begin{array}{l}\text { Mets to gingiva } \\
\text { and pleura }\end{array}$ & 1 year & DOD & 1 year \\
\hline 7 & 69 & M & Maxillary gingiva & High & $\begin{array}{l}\text { Focal } \\
\text { papillary }\end{array}$ & $\begin{array}{l}\text { Primary } \\
\text { paranasal } \\
\text { sinus }\end{array}$ & Mets to gingival & 2 years & DOD & 3 years \\
\hline
\end{tabular}

* All tumors have vasoformative areas.

$\mathrm{M}=$ male; $\mathrm{F}=$ female; mets = metastases; N/A = not applicable; DOD = died of disease; NED = no evidence for disease.

disease at a mean of 7.3 years (range, 1-13 years). The five primary salivary gland angiosarcoma patients were followed over a mean of 8.6 years, with only one patient having a late (15 years) metastasis and death (20 years), and 4 patients with no evidence of disease over a mean of 5.8 years (range, 1-14 years). Three primary (75\%) lip angiosarcoma patients revealed no evidence of disease over a mean of 14.3 years (range, 13-16 years).
Of 22 patients with primary tumors, 14 with follow-up included $5 / 8$ patients with high-grade tumors, $5 / 7$ patients with intermediate-grade tumors, and $4 / 7$ patients with low-grade tumors. Of the primary high-grade tumors with follow-up, all 5 patients had no evidence of disease over a mean of 7.6 years (range, 1-16 years). Of the primary intermediate-grade tumors with follow-up, 3 patients had no evidence of disease over a mean of 

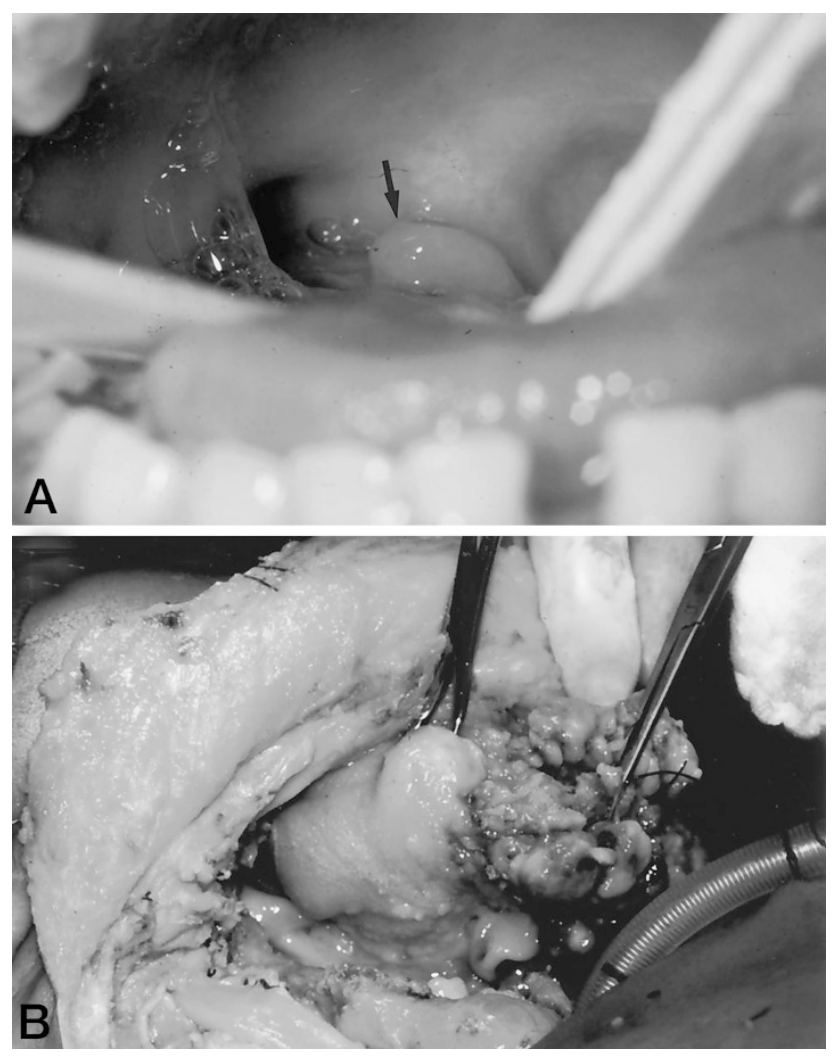

FIGURE 1. Clinical photographs of a primary tongue intermediategrade angiosarcoma in a 24-year-old woman who had no evidence for recurrence or metastasis over 11 years after radical surgical excision (A, B), arrow to clinical mass $(A)$.

12.7 years (range, 11-14 years), and two patients died of disease at 9 and 20 years. Of the primary low-grade tumors, 3 patients had no evidence of disease over a mean of 6.3 years (range, $1-14$ years), and one patient died of disease at one year.

\section{Follow-Up, Secondary (Metastatic) Angiosarcoma}

Follow-up on three secondary parotid angiosarcomas included two patients with known skin primaries and one patient with pulmonary lesions at presentation (secondary salivary gland angiosarcoma), all of whom died of disease within 1 year. All four high-grade gingival angiosarcomas represented metastases (secondary oral angiosarcoma) within 2 years from primary angiosarcoma in paranasal sinus $(n=1)$ and skin $(n=3)$; all of these patients died of disease within a mean of 2.3 years (range, 1-3 years). In summary, all patients with secondary (metastatic) tumors to the oral and salivary gland region succumbed to death from disease within 3 years.

\section{DISCUSSION}

Oral and salivary gland angiosarcoma is exceedingly rare. This study represents the largest series of oral and salivary gland angiosarcomas $(n=29)$. We wanted to study the clinicopathologic features of both primary angiosarcomas $(n=22)$ and secondary angiosarcomas $(n=7)$ because of the scarcity of angiosarcomas reported in this region.

To our knowledge, there have been only 15 total primary oral or salivary gland angiosarcomas reported in the English literature, presented mainly as single case reports. These include four primary tongue angiosarcomas $(3-5,20,23)$ one primary parotid angiosarcoma (12), one primary submandibular salivary gland angiosarcoma (21), two primary floor of mouth angiosarcomas $(13,23)$, two primary buccal mucosa angiosarcomas $(2,14)$, three primary gingival angiosarcomas $(6,16,23)$, one primary hard palate angiosarcoma (4), and one unspecified mouth angiosarcoma (4). There are no primary lip angiosarcomas in the English literature. The current series includes 22 primary angiosarcomas of oral and salivary gland location, including four primary lip angiosarcomas.

The follow-up on the primary oral and salivary gland angiosarcomas in the literature is either largely unknown or favorable, with the exception of a few cases. Many primary oral angiosarcoma patients died from unrelated causes (usually heart disease or treatment-related death) shortly after treatment of their tumor or were lost to follow-up $(5,6,13,16,20)$.

On the other hand, oral angiosarcoma patients in the literature with longer follow-up usually have relatively good outcome. A patient with a gingival angiosarcoma was alive and without evidence for disease 2 years after en bloc resection (23). The tongue angiosarcoma patient presented by Farr et al. (4) was without evidence of disease over 25 years, after wide excision. In the same series, the patient with a $1.5-\mathrm{cm}$ hard palate angiosarcoma was 16 years without evidence of disease after surgical excision (4). Likewise, a patient with a $3-\mathrm{cm}$ parotid angiosarcoma was without evidence of disease at 11 months after total parotidectomy, modified radical neck dissection, partial ear resection, and adjuvant chemotherapy (12). A buccal mucosa angiosarcoma patient was without disease at 94 months after radical surgical excision and adjuvant radiation therapy (14). Another patient with a buccal mucosa angiosarcoma, reported by Maddox and Evans (2), recurred, but the patient did well after excision of the recurrence, with no evidence for metastasis; this patient fared much better than the skin primary angiosarcomas in the same series. Therefore, the variable length follow-up, when available in these patients (4), was all relatively good, with the exception of a few cases $(1,18,21)$, including one with a $7-\mathrm{cm}$ submandibular area tumor (21) that may have started in the soft tissue 

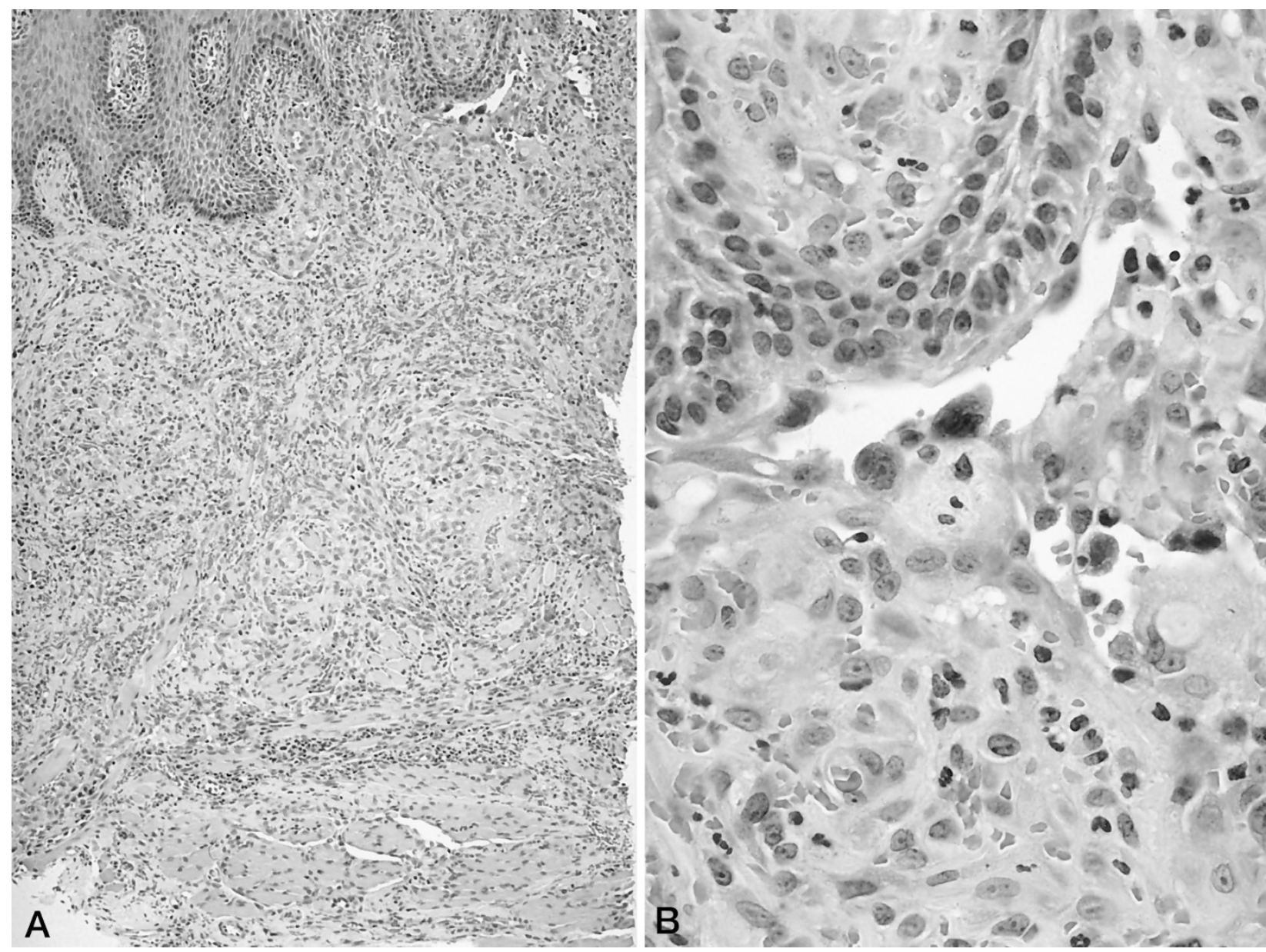

FIGURE 2. This 30-year-old woman with a primary tongue angiosarcoma had no evidence of recurrence or metastases over 13 years: infiltration of tongue skeletal muscle by solid growth of tumor (A); higher magnification of the vasoformative and focally epithelioid area of this intermediate-grade angiosarcoma, with definite cytologic atypia; other fields showed mitotic activity (B).

outside of the gland and another patient who also had a carcinoma of the floor of the mouth (1).

Our data on 22 primary oral and salivary gland angiosarcomas support the more favorable biologic behavior of angiosarcomas in these locations. Overall, 11 of the 14 primary angiosarcomas, regardless of grade, were without recurrence or metastasis over a mean follow-up period of 8.6 years (range, 1-16 years). Only two primary tongue angiosarcoma patients (at 1 and 9 years) and one parotid gland angiosarcoma patient (at 20 years) died of disease. The reasons for the generally improved behavior of oral angiosarcomas over angiosarcomas at other sites may be related to the shorter time interval to diagnosis and treatment.

In our experience, grade does not necessarily correlate with outcome of primary oral and salivary gland angiosarcomas. Interestingly, in soft tissue and skin sites, grade may also not be a predictive prognostic factor because these angiosarcomas have uniformly poor outcome (2). However, in oral and salivary gland sites, there is sometimes good outcome with high-grade and poor outcome with low-grade angiosarcomas. In fact, in this series, patients with primary angiosarcoma of tongue, salivary gland, and lip with high-grade morphology generally had quite good outcomes, with no evidence of disease over a mean of 7.6 years. Ironically, only one patient with a low-grade angiosarcoma of the tongue died of disease within 1 year, and two patients with intermediate-grade tongue and parotid angiosarcomas died within 9 and 20 years, respectively.

In comparison, primary cutaneous and deep nonoral angiosarcoma, in our data and the literature, typically has extremely poor behavior. These lesions generally exhibit metastases to lung, other skin and subcutaneous sites, bone, liver, brain, and ovary $(2,24)$, and death within 1 to 3 years. Metastases of these other angiosarcomas to oral sites are exceedingly rare, comprising only $0.1 \%$ of malignant oral neoplasms $(9,17)$.

In our experience, when these other angiosarcomas metastasize to oral cavity and salivary gland locations, they generally involve the gingiva $(n=4)$ and occasionally the parotid gland $(n=3)$. These 

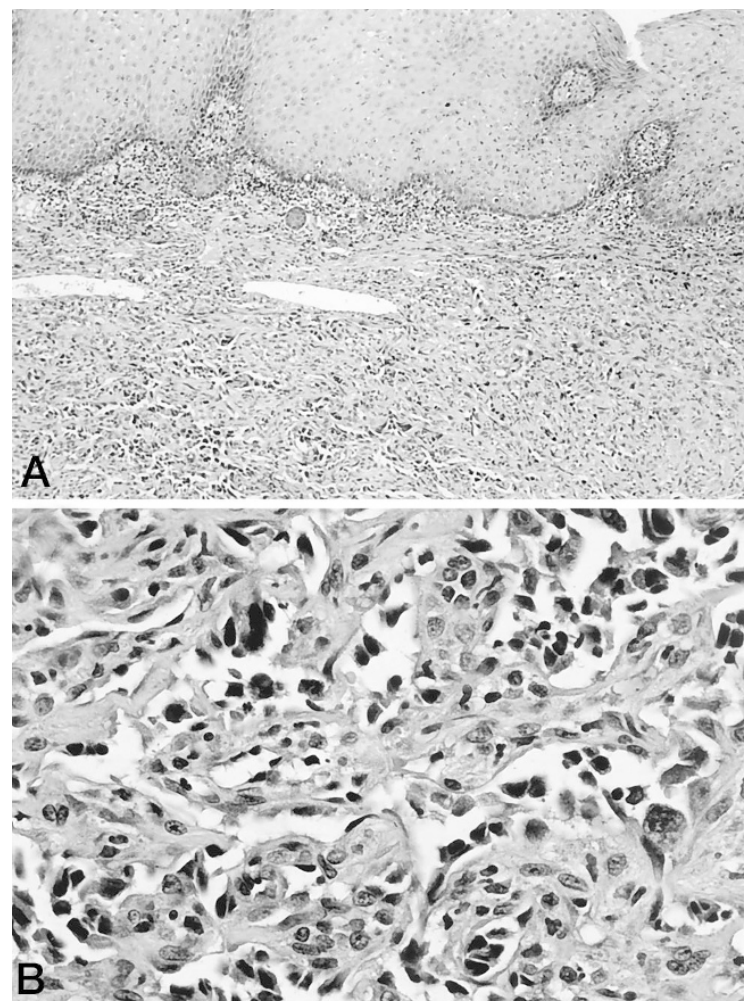

FIGURE 3. Primary tongue angiosarcoma of 62-year-old man (A) with definite endothelial atypia, mitotic activity, and dissecting vasoformative growth pattern (B)

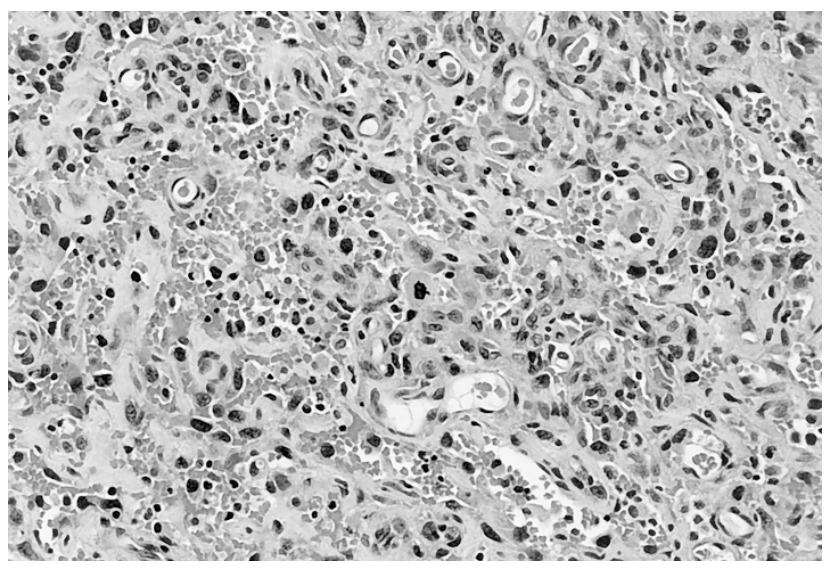

FIGURE 4. High-grade primary submandibular angiosarcoma in 59year-old man with no evidence of disease over 5 years. Note vasoformative and solid growth pattern, endothelial atypia, and mitotic activity.

gingival metastases in our series were from skin ( $n$ $=3$ ) and paranasal sinus $(n=1)$ primaries. The parotid gland metastases were from skin $(n=2)$ and presumably lung $(n=1)$ primaries. Metastatic angiosarcomas to oral and salivary gland locations have overall poor behavior, similar to the primary skin and deep soft tissue angiosarcomas described above. In the current series, all patients with met-
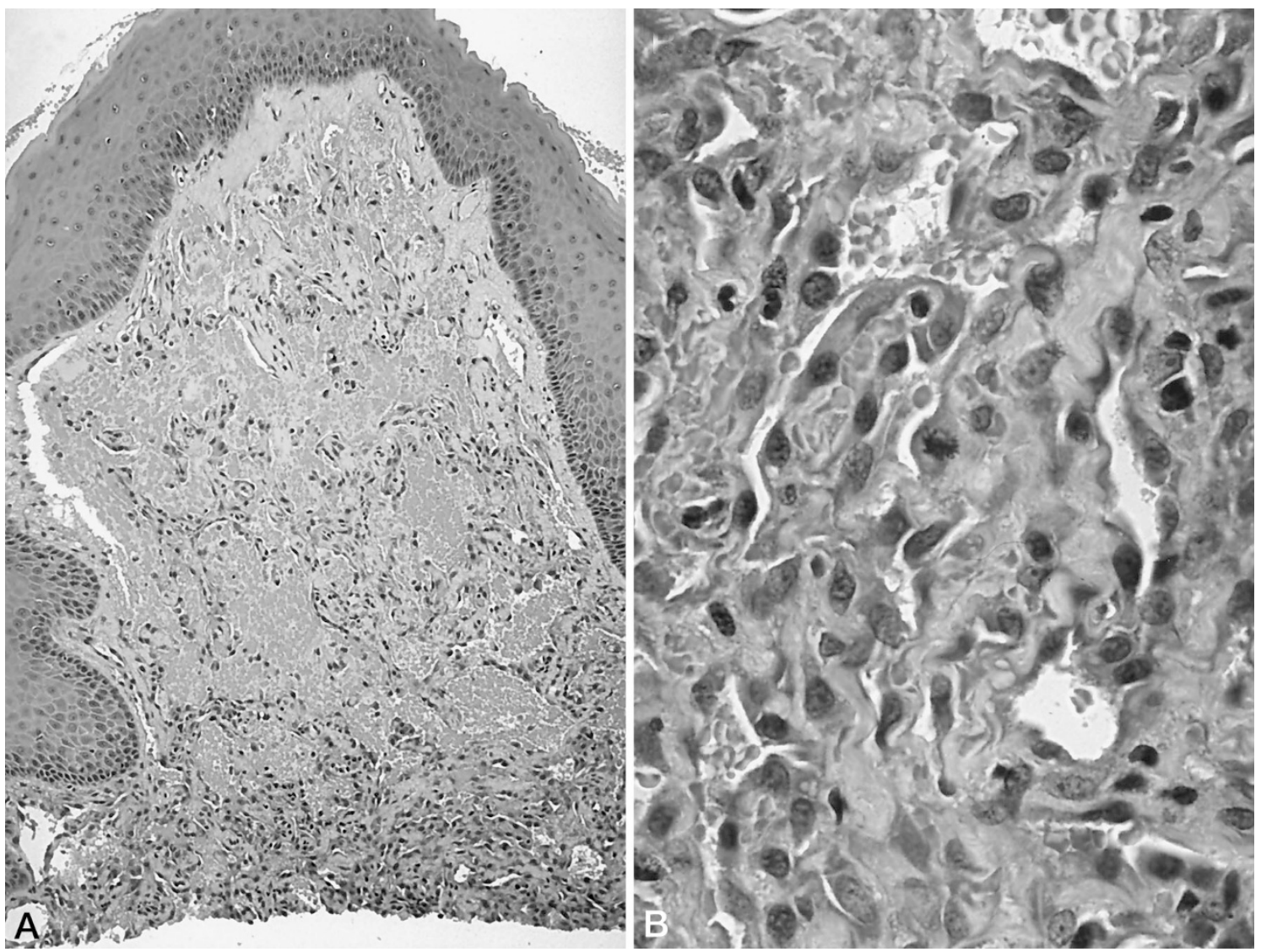

FIGURE 5. Secondary angiosarcoma to the gingiva (primary was in paranasal sinus) of 69-year-old man who had metastases and died of disease within 3 years (A); high-grade vasoformative area demonstrating endothelial atypia and mitotic activity (B). 


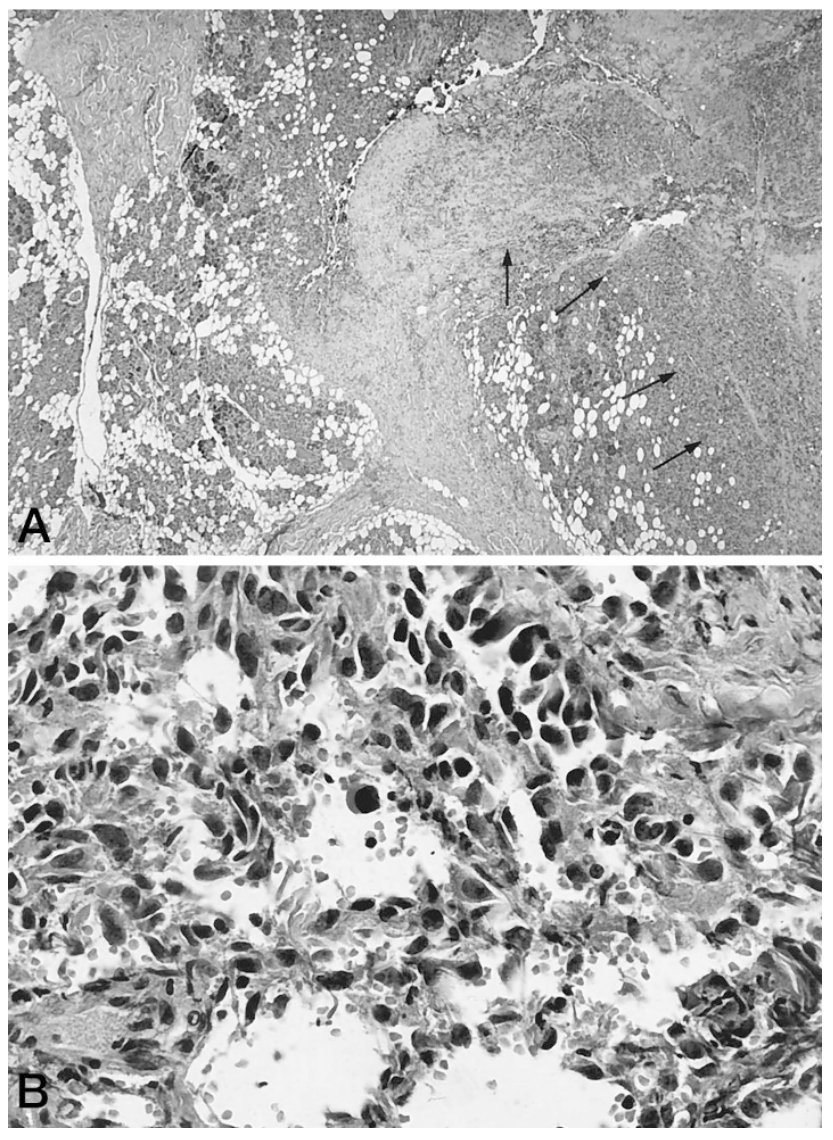

FIGURE 6. Two cases of metastatic high-grade angiosarcoma to the parotid in 71-year-old male (A, arrows to angiosarcoma, right) with higher magnification demonstrating area of vasoformative growth, endothelial atypia (arrows), and mitotic activity (right) of similar case in 72-year-old woman (B); both patients died from disease within 1 year.

astatic angiosarcoma to oral and salivary gland locations (gingiva and parotid) died of disease within 1 to 3 years.

In the literature, we found only 10 cases of metastatic angiosarcoma to the oral cavity, including 8 cases to gingiva $(1,7,9,11,17,18,22,24)$ and 2 to tongue $(8,19)$. To our knowledge, no cases of metastatic angiosarcoma to the salivary glands have been reported previously in the English-language literature, whereas the current study has three metastatic angiosarcomas to salivary gland. Previously reported metastatic tumors to oral locations have been primary from skin and subcutaneous tissue $(7$, 19), breast $(9,17,24)$, lung, kidney, bone $(1,17,22)$, colon, and uterus (11). The patients in the literature with angiosarcoma metastases to oral locations had overall poor prognosis, with metastases $(17,22,24)$ or death from disease, generally caused by respiratory compromise or bleeding, within less than 1 to 15 months (1, 7-9, 11, 18, 19). These findings on secondary oral angiosarcoma are supported by the current series, as described above. Although one tongue angiosarcoma (19) was reported as a primary, the patient also had multiple cutaneous an- giosarcomas and died within days of his hospital stay, a course more consistent with primary angiosarcoma of skin.

The importance of including our seven secondary (metastatic) angiosarcoma to the oral cavity and salivary gland in the current series is to warn the pathologist and clinician of the potential that these oral and even salivary gland angiosarcomas could be metastatic or secondary and therefore have much worse prognosis than if they were primary to these locations.

Of patients in the literature with primary, uncomplicated oral or salivary gland angiosarcoma, surgical treatment is best $(19,25,26)$. Radiation therapy and chemotherapy in these tumors has been proven to be largely ineffective, unless the chemotherapy is given intra-arterially $(20,21,25)$. In our experience, only three patients with high-grade tumors were known to receive adjuvant therapy, leaving the remaining patients who did well with surgical excision alone.

Although radiation-induced angiosarcomas have been reported to occur in the oral cavity and salivary gland locations, there were no known radiation-induced angiosarcomas in the current series. Two cases reported in the English-language literature include a radiation-induced angiosarcoma of the tongue, 30 years after radiation therapy for a lymphangioma of the tongue (25), and a radiation-induced high-grade angiosarcoma of the parotid, 12 years after irradiation for laryngeal squamous cell carcinoma (15). Radiation-induced angiosarcomas of the oral cavity, like non-oral primary angiosarcomas, are reported to behave poorly (25), with early onset of metastases and death within 2 years after treatment (25).

Morphologically, oral and salivary gland angiosarcoma differ from that of angiosarcoma elsewhere. Although the most common angiosarcoma morphology in the oral and salivary gland location is spindled vasoformative and solid, one third of oral and salivary gland angiosarcomas in this series (23\% of the primary tumors) and in the literature are the unusual epithelioid angiosarcoma variant. The epithelioid subtype is composed of plump atypical round cells with prominent nucleoli and definite intracytoplasmic lumina containing red blood cells (i.e., epithelioid endothelial cells). The large percentage of epithelioid angiosarcoma in primary oral angiosarcoma in the current series supports the findings in the literature, with incidence of $33 \%$. Three $(16,21,23)$ of nine $(2,5,6,12,13,20)$ primary oral or salivary gland angiosarcomas in the literature specifically demonstrated or reported epithelioid subtype of angiosarcoma. We were not able to stain all of our epithelioid angiosarcomas with epithelial markers, but the literature described keratin reactivity in approximately $30 \%$ of epithe- 

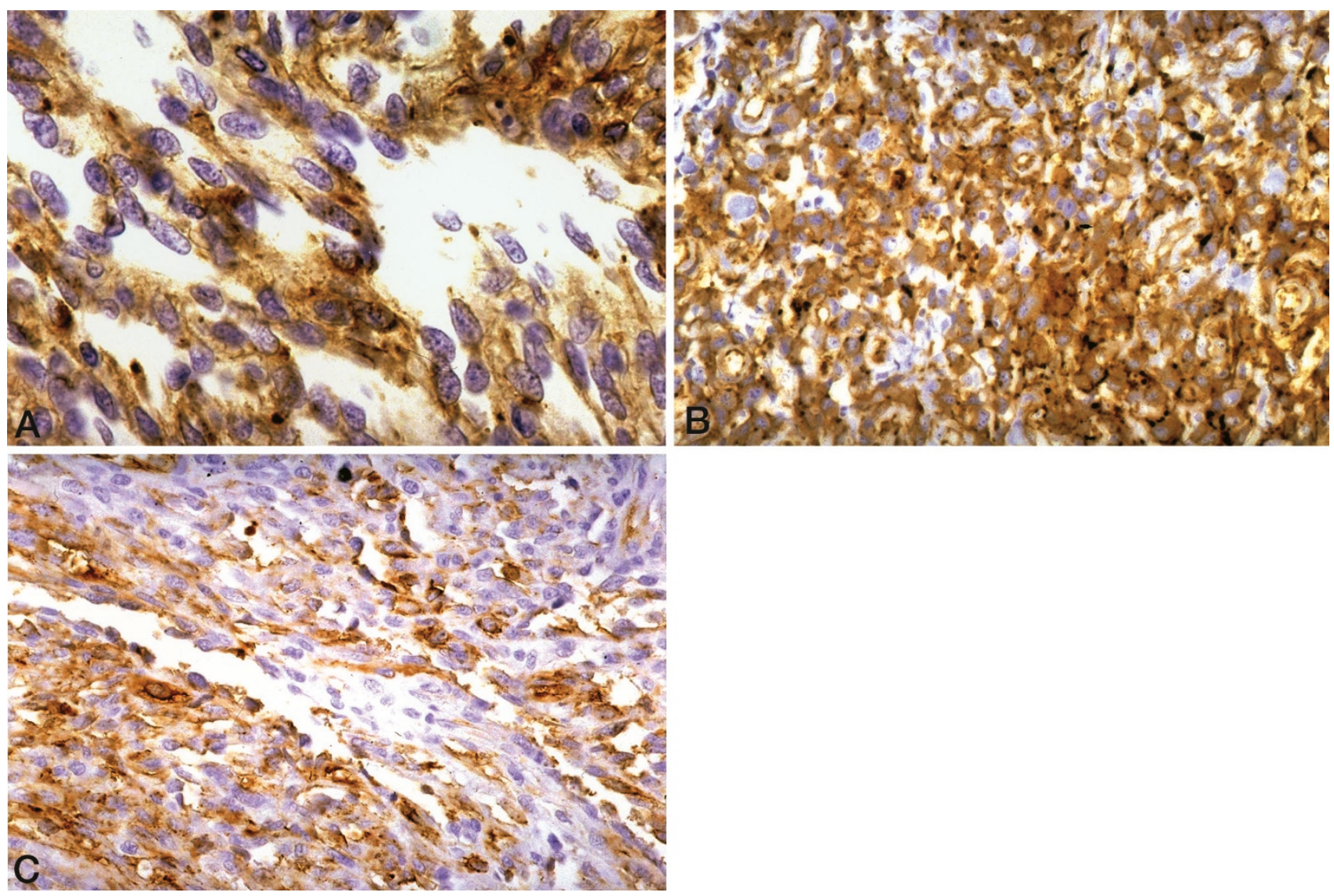

FIGURE 7. Immunohistochemical stains on angiosarcomas: strong diffuse Factor VIIIrag in 19/21 cases (A) and CD31 in 16/19 cases (B), yet more focal and not as reliable CD34 in $7 / 12$ cases $(\mathbf{C})$.

lioid angiosarcoma in other locations (28). Awareness of this increase in epithelioid morphology in oral/salivary gland angiosarcoma would be helpful for the pathologist, as several epithelioid tumors may be in the differential diagnosis.

Proving the vascular phenotype, particularly in tumors with non-vasoformative areas, is essential for diagnosis. Although Factor VIIIrag successfully has been used to diagnose vascular phenotype (13, 16), CD31, a membrane glycoprotein that mediates endothelial cell interactions and promotes vascular adhesion of leukocytes, is the best vascular marker for endothelial phenotype, particularly in poorly differentiated angiosarcoma, when Factor VIIIrag and Ulex europaeus fail $(12,20)$. In our experience, these two markers were more reliable than CD34 for angiosarcoma. CD34 is known to have low specificity (12) and low sensitivity. Although some reports of oral angiosarcoma are CD34 reactive (15), the current series and the experience of others (20) found CD34 to be less reactive than CD31 or Factor VIIIrag.

It is significant that in this location, the differential diagnosis for angiosarcoma includes hemangioma, pyogenic granuloma (1), hemangiopericytoma, fibrous histiocytoma, Kaposi's sarcoma, hemangioendothelioma, epithelioid sarcoma, ma- lignant melanoma, and other epithelioid neoplasms. True vasoformative foci, endothelial atypia, mitotic activity, collagen dissection, and infiltrative growth pattern separate these tumors from benign mimics. Lack of cytoplasmic hyaline globules, spindled cells with distinctive cytoplasmic borders, and scattered plasma cells distinguish angiosarcoma from Kaposi's sarcoma. The vascular markers separate angiosarcoma from carcinoma and melanoma, although keratins may be observed in epithelioid endothelial tumors. Finally, separating angiosarcoma from hemangioendothelioma, particularly the epithelioid subtype and the low-grade variants, can be challenging, yet the latter lesion has a very distinctive growth pattern of cords to sheets of epithelioid endothelial cells with a remarkable hyaline stroma. These features were absent in our angiosarcomas and particularly in the angiosarcomas with epithelioid features, and true cytologic atypia and collagen dissection were always present.

In conclusion, oral and salivary gland angiosarcomas are rare tumors in adults that generally behave more favorably than do angiosarcomas in other locations, regardless of grade. This is the first report of primary lip angiosarcomas and metastatic angiosarcoma to a salivary gland location. This 
study confirms the relatively good outcome for oral and salivary gland angiosarcomas compared with angiosarcomas elsewhere (skin and deep soft tissue). Because primary oral and salivary gland angiosarcomas generally tend to behave better than usual angiosarcoma from other locations, complete surgical excision is the preferred treatment for these angiosarcomas.

\section{REFERENCES}

1. Munoz M, Monje F, Alonso del Hoyo JR, Martin-Granizo R. Oral angiosarcoma misdiagnosed as a pyogenic granuloma. J Oral Maxillofac Surg 1998;56:488-91.

2. Maddox JC, Evans HL. Angiosarcoma of skin and soft tissue: a study of forty-five cases. Cancer 1981;48:1907-21.

3. Barnes L. Surgical pathology of the head and neck. Vol 1. New York: Marcel Dekker; 1985. p. 826-31.

4. Farr HW, Carandang CM, Huvos AG. Malignant vascular tumors of the head and neck. Am J Surg 1970;120:501-4.

5. Frick WG, McDaniel RK. Angiosarcoma of the tongue: report of a case. J Oral Maxillofac Surg 1988;46:496-8.

6. Albright CR, Shelton DW, Vatrall JJ, Hobin FC. Angiosarcoma of the gingiva: report of a case. J Oral Surg 1970;28:913-7.

7. Carr RJ, Green DM. Oral presentation of disseminated angiosarcoma. Br J Oral Maxillofac Surg 1986;24:277-85.

8. Crymes T, Taylor RG. Angiosarcoma metastatic to the tongue: report of a case. J Oral Surg 1966;24:63-6.

9. Epstein JB, Knowling MA, Le Riche JC. Multiple gingival metastases from angiosarcoma of the breast. Oral Surg Oral Med Oral Pathol 1987;64:554-7.

10. Esparza-Gomez G, Aguirre JM, Cerero R, Moreno L, Llanes F. Primary angiosarcoma of the gingiva. Med Oral 1996;1:110-3.

11. Medina BR, Barba EM, Torres AV, Trujillo SM. Gingival metastases as first sign of a primary uterine angiosarcoma. J Oral Maxillofac Surg 2001;59:467-71.

12. Mullick SS, Mody DR, Schwartz MR. Angiosarcoma at unusual sites. A report of two cases with aspiration cytology and diagnostic pitfalls. Acta Cytol 1997;41:839-44.

13. Oliver AJ, Gibbons SD, Radden BG, Busmanis I, Cook RM. Primary angiosarcoma of the oral cavity. Br J Oral Maxillofac Surg 1991;29:38-41.

14. Pandey M, Thomas G, Mathew A, Abraham EK, Somanathan $\mathrm{T}$, Ramadas $\mathrm{K}$, et al. Sarcoma of the oral and maxillofacial soft tissue in adults. Eur J Surg Oncol 2000;26:145-8.
15. Perez del Rio MJ, Garcia-Garcia J, Diaz-Iglesias JM, Fesno MF. Radiation-associated angiosarcoma involving the parotid gland. Histopathology 1998;33:586-7.

16. Piscioli F, Leomardi E, Scappini P, Cristofolini M. Primary angiosarcoma of the gingiva. Case report with immunohistochemical study. Am J Dermatopathol 1986;8:430-5.

17. Poulopoulos AK, Antoniades K, Kiziridou A. Bilateral metastatic breast angiosarcoma to the mandibular gingiva: case report. Oral Oncol 2001;37:199-201.

18. Quinn JH, McConnell HA Jr, Leonard GL. Multifocal angiosarcoma of the gingiva: report of a case. J Oral Surg 1970;28: 215-7.

19. Rao KK, Kumar HN, Rao RV. Primary haemangiosarcoma of the tongue. Int J Oral Maxillofac Surg 1986;15:489-91.

20. Tabata M, Sugihara K, Matsui R, Yonezawa S, Aeyama K, Maruyama I. Angiosarcoma of the tongue: report of a case with immunohistochemical findings. J Oral Pathol Med 1999;28:92-5.

21. Tomec R, Ahmad I, Fu YS, Jaffe S. Malignant hemangioendothelioma (angiosarcoma) of the salivary gland: an ultrastructural study. Cancer 1979;43:1664-71.

22. Toth BB, Fleming TJ, Lomba JA, Martin JW. Angiosarcoma metastatic to the maxillary tuberosity gingiva. Oral Surg Oral Med Oral Pathol 1981;52(1):71-4.

23. Wesley RK, Mintz SM, Wetheimer FW. Primary malignant hemangioendothelioma of the gingiva-report of a case and review of the literature. Oral Surg 1975;39:103-12.

24. Win KK, Yasuoka T, Kamiya H, Jinno T. Breast angiosarcoma metastatic to the maxillary gingival. Case report. Int J Oral Maxillofac Surg 1992;21(5):282-3.

25. Yasumatsu R, Hiakawa N, Tomita K. Postradiation angiosarcoma of the tongue. Eur Arch Otorhinolaryngol 2000;257(8): 464-5.

26. Wanebo HJ, Koness RJ, MacFarlane JK, Eilber FR, Byers RM, Elias EG, et al. Head and neck sarcoma: report of the Head and Neck Sarcoma Registry. Society of Head and Neck Surgeons Committee on Research. Head Neck 1992;14(1):1-7.

27. Coindre JM, Terrier P, Guillou L, Le Doussal V, Collin F, Ranchere D, et al. Predictive value of grade for metastasis development in the main histologic types of adult soft tissue sarcomas: a study of 1240 patients from the French Federation of Cancer Centers Sarcoma Group. Cancer 2001;91(10): 1914-26.

28. Weiss SW, Goldblum JR, editors. Enzinger and Weiss's soft tissue tumors. 4th ed. St. Louis, MO: Mosby; 2001. p. 934. 